\title{
COLÉGIO ESTADUAL PAES DE CARVALHO: REGISTROS SOBRE A PRESENÇA NEGRA NA EDUCAÇÃO ESCOLAR PARAENSE (1931-1942)
}

\author{
Bianca Ferreira de Oliveira ${ }^{1}$ \\ Universidade Federal do Pará - UFPA \\ oliveira_biancaferreira@hotmail.com
}

\section{RESUMO}

Este artigo apresenta dados a respeito da participação da figura negra na educação escolar paraense a partir do Colégio Estadual Paes de Carvalho no período de 1931 a 1942. A pesquisa foi realizada no arquivo do Colégio Estadual Paes de Carvalho e utilizou como fonte o livro para registro de historico de funccionarios, aberto em 1933, sob a direção do Professor Honorato Filgueiras. Inicialmente, discute acerca das relações entre a pessoa negra e a educação no Estado do Pará. Em seguida, apresenta aspectos do Colégio Estadual Paes de Carvalho em relação sua história. Por fim, propõe algumas reflexões a respeito da presença negra no quadro de funcionários da escola, onde, na maioria dos casos, ocupavam o cargo de servente.

Palavras-chave: História da Educação Paraense; História das Instituições Escolares; Negros no Pará.

\section{STATE COLLEGE PAES DE CARVALHO: RECORDS OF THE BLACK PRESENCE IN PARAENSE SCHOOL EDUCATION (1931-1942)}

\begin{abstract}
This article presents data of the participation of the black figure in school education Pará from State College Paes de Carvalho in the period from 1931 to 1942. The research was conducted in State College Paes de Carvalho archive and used as a source book for registry of historic functionaries, opened in 1933, under the direction of Teacher Honorato Filgueiras. Begins by discussing about the relationship between the black person and education in the State of Pará. It then presents aspects of State College Paes de Carvalho regarding your story. Finally, it proposes some reflections about the black presence in the school's staff, which, in most cases, occupied the office of servant.
\end{abstract}

Keywords: History of Pará Education; History of School Institutions; Blacks in Pará.

\section{INTRODUÇÃO}

O presente artigo foi construído a partir das pesquisas documentais realizadas para a construção da minha dissertação de mestrado, em andamento. Tem como principal objetivo apresentar dados a respeito da participação da figura negra na educação escolar paraense a partir do Colégio Estadual Paes de Carvalho (CEPC) no período de 1931 a 1942. Os demais objetivos podem ser destacados em: a) discutir acerca das relações entre a pessoa negra e a educação no Estado do Pará; b) apresentar aspectos do Colégio Estadual Paes de Carvalho em relação a sua história; c) propor reflexões a respeito da presença negra no quadro de funcionários do Colégio Estadual Paes de Carvalho². 
Para fins de análise e coleta dos dados, foi adotada a pesquisa do tipo documental, e recorreu-se às orientações teórico-metodológicas propostas por Le Goff (1990), que afirma que

O documento não é qualquer coisa que fica por conta do passado, é um produto da sociedade que o fabricou segundo as relações de forças que aí detinham o poder. Só a análise do documento enquanto monumento permite à memória coletiva recuperá-lo e ao historiador usá-lo cientificamente, isto é, com pleno conhecimento de causa (LE GOFF, 1996, p. 545).

Ou seja, Le Goff (1996) ressalta a importância de analisar o documento em todo o seu contexto, considerando as relações de poder que envolvem a sua construção, tomandoo, ao mesmo tempo, como verdadeiro e falso, pois, sendo monumento, ele "resulta do esforço das sociedades históricas para impor ao futuro - voluntária ou involuntariamente determinada imagem de si próprias"; cabendo ao pesquisador "não fazer papel de ingênuo" (p. 48).

Também se recorreu, como orientação metodológica, ao que propõe Rodríguez (2010, p. 40):

[...] um dos primeiros passos para o estudo histórico e a leitura crítica dos documentos é a realização de um levantamento bibliográfico que vise a aprimorar o conhecimento produzido a respeito do objeto de pesquisa, permitindo reconhecer as contribuições temáticas e identificar lacunas na produção existente.

Neste sentido, o esforço em realizar o levantamento bibliográfico proposto pela autora, resultou nas considerações apresentadas no item 2 deste artigo - "O Colégio Estadual Paes de Carvalho" - e tiveram como referência: França (1997), Rego (2002), Chaquiam; Gaspar e Borges (2010) e Ribeiro (2013).

A coleta de dados foi realizada no período de dezembro de 2014 a abril de 2015 no arquivo do CEPC, localizado em sala anexa à secretaria da escola. O arquivo, já com muitos documentos em estado de deterioração - situação semelhante a outros arquivos, como afirma Rodriguez (2010), guarda uma enorme quantidade de fontes que podem ajudar a construir e consolidar a História da Educação Paraense. De acordo com esta autora, as fontes aqui utilizadas podem ser classificadas como "fontes escritas", que são aquelas

[...] realizadas sobre material duro ou em pedra; também sobre material brando (papiro, pergaminho ou papel, códices ou documentos soltos); ou fontes impressas (crônicas, históricas, coleções de documentos, edições críticas de manuscritos). Essas fontes são também chamadas de documentais (RODRÍGUEZ, 2010, p. 42).

Atas de reuniões e concursos, provas, boletins, históricos escolares, livros de pontos, nomeações, dentre outros - atuais e do século XIX -, compõem o acervo, porém, para este trabalho, foi utilizado como principal fonte o Livro para registro de historico de funcionários $\left(\mathrm{n}^{\circ} 1\right)$, aberto no ano de 1933, quando a escola estava sob a direção do Professor Honorato Filgueiras.

O Livro para registro de historico de funcionários $\left(\mathrm{n}^{\mathrm{o}} 1\right)$ se constitui como uma importante fonte para a história não apenas do Colégio Estadual Paes de Carvalho, mas de seus funcionários. Nele, estão contidas informações acerca do histórico profissional anterior ao ingresso dos trabalhadores no CEPC e registros de nomeação, promoção, transferência e 
exclusão na instituição, e foi trabalhado na obra de Clóvis Moraes Rêgo "Subsídios para a história do colégio estadual 'Paes de Carvalho'", em 2002.

Dentre os funcionários presentes nos registros, estavam docentes, serventes, inspetores e, nesse universo, foram identificados 05 que apresentavam uma característica em comum: ser negro. Esta seleção dos sujeitos foi feita levando em consideração o item "cor" presente na seção "sinais" da ficha individual de cada um, sendo elencados para compor o estudo os que apresentavam a cor "preta", "parda" ou "morena".

Esta escolha se justifica pelo contexto social da época, em que o preconceito racial era teoricamente sustentado - pelo positivismo e evolucionismo - e compunha a política e educação nacional e local. Moraes (2011) destaca a importância de José Veríssimo na construção desse ideário que, pautado no evolucionismo, "concebia a população paraense composta da mistura racial entre negros e indígenas em sua maioria, como sendo degenerada racialmente" (p. 58).

O recorte cronológico tomou como base os anos das nomeações dos funcionários caracterizados como "pretos", "pardos" ou "morenos" presentes no Livro para registro de historico de funcionários ( $\left.\mathrm{n}^{\circ} 1\right)$, tendo sido admitido o primeiro, na instituição, no ano de 1931 e o último, em 1942.

As contribuições apresentadas a seguir constituem-se como uma proposta de reflexão acerca da participação negra na educação paraense, não tendo a pretensão de dar respostas acabadas ao problema do preconceito racial no âmbito educacional, mas busca somar aos estudos que já vem sendo desenvolvidos na temática.

\section{O NEGRO E A EDUCAÇÃO NO CONTEXTO PARAENSE}

Para realizar um breve panorama da história do negro e tentar estabelecer algumas relações com o contexto educacional paraense, trago algumas considerações tomando como base três momentos: a) o de predominância do sistema escravocrata (em Belém, do início do século XVII ao final do XIX); b) o da Primeira República Paraense (1889-1930); c) o das revoluções no âmbito educacional e social (a partir de 1931).

Ainda que falar acerca da introdução da pessoa negra no Brasil a partir do regime escravocrata pareça um assunto já esgotado, faz-se necessário realizar um breve retorno para entender algumas particularidades da chegada dessa população no Pará. Sobre isto, SALLES (1971, p. 5) afirma que

[...] aceitava-se o prêto escravo que deveria ocupar o lugar dos gentios nos trabalhos da lavoura. A experiência no Estado do Brasil, onde o negro substituiu vantajosamente o braço indígena, deve ter estimulado essa resolução ou inspirado seus proponentes. Contudo, condições especiais da Amazônia, sobretudo uma lavoura incipiente, que prosperava com lentidão, retardaram a organização do tráfico.

Inicialmente, por questões "naturais", o negro não foi tão visado para a mão-de-obra na Amazônia e, especificamente no Pará. Contudo, as motivações religiosas, políticas e econômicas, posteriormente, levaram, sob forte influência dos jesuítas, que já estavam em missão em Belém, à "troca" do indígena pelo negro no sistema escravocrata, apresentando a seguinte justificativa:

O negro fôra escravo em todos os tempos e já o era entre os seus. Pela organização do trabalho colonial, não podia ser dispensado o braço servil. Que se sacrificasse, portanto, o africano em benefício da raça que os 
jesuítas queriam redimir e que já lhes houvera custado sacrifício sem par! Propunha pois uma troca. (SALLES, 1971, p. 5).

Esta troca não se estabeleceu com ausência de conflitos, Salles (1971) afirma que houve resistência por parte dos colonos que preferiam a mão-de-obra indígena, pois além de raro na região, o escravo negro lhes custaria um valor bem mais elevado em relação ao "tráfico vermelho". Outros conflitos também podem ser percebidos no que diz respeito às "forças" às quais o negro estava submetido na sociedade escravocrata, havia uma dissonância expressiva, principalmente, entre as leis da metrópole, a "lei" do senhor de escravos e, em casos particulares, a legislação das missões que, algumas vezes, tomavam suas decisões sem considerar as "Ordenações do Reino". Este autor sinaliza essa contradição apontando para o fato de existir um tratamento individual que os negros escravizados recebiam de seus senhores: "A lei [...] era pública, regulava a vida pública do cidadão e do escravo; não ingressava no lar de cada um. Aí imperava [...] o Senhor, e a vida doméstica estava sujeita aos seus caprichos" (SALLES, 1971, p. 113).

Vicente Salles (1971) trata a questão da presença negra do Pará a partir do século XVII e enfatiza a influência dessa população no estado que, embora pequena em número, foi expressiva na formação cultural e étnica, e vai contra a ideia de que no Pará o principal elemento da constituição do povo é o indígena. Afirmando que, embora em minoria quantitativa, o negro "não deixou de plasmar aí sua personalidade, de influir étnica e culturalmente, além de constituir, durante todo o regime da escravidão, o suporte da economia agrária" (SALLES, 1971, p. VII).

Sobre a instrução neste período, primeiramente durante a fase de colônia, Rego (2002, p. 218), afirma que esta, até 1751 , esteve sob a responsabilidade exclusiva dos jesuítas, tendo estes fundado um colégio religioso, e que, de 1752 a 1821 pouco ou nenhum esforço foi envidado em prol da instrução, pois "a ignorância favorecia as ambições dos que dominavam e dos que queriam dominar, por isso era mantida com indiferença pela maioria da população". Este autor ressalta, logo em seguida, que ainda no período imperial os investimentos em educação eram irrisórios, havendo em Belém "apenas duas escolas de ensino de primeiras letras pelo sistema de ensino mútuo para o sexo masculino e uma para o sexo feminino". Acerca da instrução nas localidades do interior, é mencionado apenas o ensino de Gramática Latina em Vigia, Cametá e Santarém.

Avançando um pouco mais, chegamos ao período que compreende os anos de 1889 a 1930, conhecido como Primeira República ou República Velha, no Brasil, e que marca um importante momento de transição política e econômica, e de ruptura com a forma de governo vigente até então, o imperialismo. No Estado do Pará, o ideário republicano já permeava a elite política e econômica desde meados da década de 1880. Neste período, o pensamento positivista e evolucionista encontra lugar nos debates da comunidade letrada paraense e influencia no modo de analisar a sociedade e a política local.

Sobre a formação intelectual daqueles que estiveram à frente do movimento de implantação da república no Pará, Moraes (2011) apresenta o Club Republicano do Pará e o jornal "A República" como importantes locais de articulação e difusão dos ideais republicanos, que tinham como base teórica as concepções evolucionistas e positivistas, à época, representação da inovação científica que serviu como instrumento para o confronto e negação do imperialismo. Assim, em 1886, é publicado no jornal "A República", o "Manifesto do Club Republicano do Pará", contendo críticas ao governo imperial (MORAES, 2011).

Dentre o conjunto de características do império que foram alvo de críticas pelo movimento republicano no Pará, estão a centralização política e administrativa, a influência 
religiosa na sociedade e a economia escravista (já superada em tantos países), que, portanto, deixavam o Brasil fora dos "padrões da modernidade". No entanto, é necessário ressaltar que essa visão de atraso fora construída tomando como base as concepções de ciência e sociedade positivistas. Este pensamento, o positivismo, representou, na sua época, o avanço da ciência, o desprendimento com a religião no âmbito do conhecimento, acompanhando a consolidação da sociedade moderna.

No que concerne às influências das teorias raciológicas no pensamento republicano, Moraes (2011) salienta os estudos de Darwin sobre a evolução das espécies - ao afirmar a superioridade de determinadas raças, ou atributos biológicos, em detrimento de outras como sustentáculo para as teorias do evolucionismo cultural e darwinismo social, que acabaram por legitimar as práticas e discursos racistas no âmbito social, político e, consequentemente, reproduzidos no campo educacional.

Considerando esta forma de pensamento republicano apresentado no estudo de Moraes (2011) e visível na obra de José Veríssimo (1985), é possível identificar que concepção se tinha a respeito da população brasileira e paraense, em especial, de um povo degenerado pela mestiçagem do europeu com os indígenas e africanos e, por consequência, preguiçoso, indolente, inculto, portador de todos os tipos de vícios, que, por sua vez, era o responsável pelo atraso do Brasil em relação à sociedade moderna.

Tendo este ideário certo amadurecimento, em 1889, é iniciado, no Pará, o primeiro governo republicano, o Governo Provisório de Justo Chermont, que durou até 1891, seguido pelo Primeiro Governo de Lauro Sodré (1891 - 1897). Ambos envidaram seus esforços para a consolidação do regime republicano no estado e, além da participação da imprensa, como já mencionado anteriormente com o jornal "A República" e a publicação do "Manifesto do Club Republicano do Pará", a educação foi um importante meio na tentativa de alcançar este objetivo. Para isso, diversas reformas educacionais foram propostas (MORAES, 2011), dentre elas, a equiparação do Liceu Paraense ao Ginásio Nacional com o intuito de elevar o nível da educação e possibilitar o ingresso dos jovens na educação superior.

"Até 1930 as necessidades do país ainda comportavam, com a oligarquia no poder, um tipo de educação voltada para a satisfação dos interesses oligárquicos: ornamento cultural, preenchimento dos quadros da burocracia de Estado e das profissões liberais. Neste sentido, amplas camadas da população eram marginalizadas do processo educativo escolar. A educação atende exclusivamente as "elites"” (CURY, 1988, p. 18).

Cury (1988), no trecho acima, sintetiza como o contexto educacional se configurou, em seus objetivos políticos e econômicos, no período da Primeira República a nível nacional, caracterizando-o como um momento de "entusiasmo pela educação", em que o ensino era oferecido para formação de força produtiva eficaz, para tornar os cidadãos aptos ao voto, recebendo educação de fato apenas as elites, sendo excluídos os negros, indígenas, pobres, mestiços e grande parte da camada popular da sociedade.

A partir de 1930, Cury (1988, p. 19) afirma ter ocorrido uma mudança na concepção de educação, os movimentos pautados no "entusiasmo pela educação" são julgados como defensores de uma educação prática para o avanço nacional, contudo, a "ampla" disseminação não seria suficiente para "superar o atraso e a ignorância" da população. Surge então, o "otimismo pedagógico", propondo a reforma das escolas, apregoando os ideais da escola nova, onde

a escola seria mais eficiente, seu espírito científico qualificaria o ensino, a psicologização do processo educacional capacitaria o aluno segundo suas 
virtualidades, a administração escolar racionalizaria o processo educacional. Enfim, começa a se fazer presente no Brasil a idéia de Reconstrução social pela Reconstrução educacional (CURY, 1988, p. 19).

Os princípios desse movimento, expressos no "Manifesto dos pioneiros da Educação Nova" (1932), apesar de todas as inovações propostas, iria intensificar as desigualdades sociais e educacionais já existentes, pois a elite não aceitaria o novo modelo de educação e, com isso, "formar-se-iam 'duas redes de ensino': aquela que atenderia a formação das 'elites' e a que atenderia a formação da força de trabalho" (idem, p. 19), ou seja, os que já eram excluídos do processo educacional permaneceriam na mesma situação, salvo algumas exceções.

\section{O COLÉGIO ESTADUAL PAES DE CARVALHO}

Inaugurado em 28 de julho de 1841, o Colégio Estadual Paes de Carvalho (CEPC), com seus mais de 170 anos, figura como um importante centro de formação da intelectualidade paraense desde o século XIX. De seu corpo docente e discente, saíram grandes nomes da história do Estado do Pará, dentre eles, educadores influentes no campo teórico e político, médicos, jornalistas, escritores, advogados, diversos governadores, ministros e demais cargos públicos, como Clóvis Moraes Rego, Dalcídio Jurandir, Gaspar Viana, Lauro Sodré, Justo Chermont, entre outros.

Toda a trajetória que foi e, ainda hoje, vem sendo construída pelo Colégio Estadual Paes de Carvalho, consolidou a tradição que permeia a instituição, sobretudo nos seus anos áureos, que Ribeiro (2013, p. 58) define como o

[...] passado glorioso, da era de ouro quando o colégio foi referência em qualidade do ensino, respeitado e reconhecido local, regional e nacionalmente, por ter formado grandes nomes da cena pública paraense, por ter o melhor e mais competente corpo docente; rememora, ainda, as vitórias e prêmios conquistados, tudo por que um dia foi equiparado ao colégio da Corte, o Pedro II. (RIBEIRO, 2013, p. 58).

Clóvis Moraes Rego, que foi professor da instituição a partir da década de 1940, ressalta outro fator importante a ser considerado quando se pensa a construção da tradição do Colégio Paes de Carvalho, o tão ostentado "ensino de qualidade", por ter seu corpo docente caracterizado por ele como "um viveiro de eruditos, de iluminados, de gigantes pelo saber e pela opulência moral. $\mathrm{O}$ acesso aos novos não era fácil senão quase impossível. Tentá-lo valia arriscar-se a duro e penoso crivo" (REGO, 2002, p. 43). Pode-se inferir, então, que este rigor na seleção de seus educadores proporcionava aos que passavam pelo "duro e penoso crivo" um status social, sobretudo em determinados períodos históricos, como no caso da Primeira República.

Ainda que possa parecer ter perdido a força de sua tradição com o tempo e consequentes mudanças culturais, o CEPC guarda elementos que a sustentam, tais como seus traços arquitetônicos tombados pelo Instituto de Patrimônio Histórico e Artístico Nacional (IPHAN); as escadas diferenciadas para alunos do sexo feminino e masculino; a atenção dedicada às apresentações nos desfiles escolares; o tradicional uniforme - calça azul marinho, blusa branca e sapatos pretos para os rapazes, saia plissada azul marinho, blusa branca, sapatos pretos e meias brancas para as moças - que, apesar de mantido, é reinventado cotidianamente pelos alunos por meio de customizações e uso de acessórios ${ }^{3}$ (RIBEIRO, 2013). 
Retornando ao momento de inauguração do Colégio Estadual Paes de Carvalho, à época "Liceu Paraense", França (1997, p. 120) traz algumas informações que apresentam o contexto educacional nesse período, mostrando a situação de abandono do ensino secundário na Província do Grão-Pará, a partir do relatório de Bernardo de Souza Franco, presidente da província, direcionado à Assembleia Legislativa no ano de 1839, contando com "uma aula de Filosofia Racional e Moral, uma de Retórica, quatro de Latim e uma de Francês, encontrando-se estas últimas sem provimento", sendo este o "saldo das "Aulas Régias" criadas a partir das Reformas Pombalinas da Instrução Pública”.

Ao ser inaugurado, em 28 de julho de 1841, o então "Liceu Paraense" teve como endereço o $n^{\circ} 26$ do Largo do Palácio. Em 1843, mudou-se para a Travessa do Passinho, $n^{\circ}$ 31, no canto da Rua Nova de Sant'Anna. Em seguida, funcionou no Convento do Carmo. Por fim, em 1871, passou a ter instalações próprias na Praça Saldanha Marinho, Bairro da Campina, em Belém, onde permanece atualmente (REGO, 2002).

As transformações sofridas pelo CEPC não ficaram apenas no âmbito físico, mas, sobretudo, no campo curricular. Dentre as principais reformas vivenciadas pela escola, destaca-se a equiparação do "Liceu Paraense",

no seu plano de ensino integral, ao Gymnasio Nacional, de acordo com as modificações operadas pelo Ministro da Instrução Pública, Benjamin Constant. Essa equiparação trouxe muitas vantagens, de acordo com Lauro Sodré, que, seguindo a mesma natureza do curso daquela instituição em âmbito nacional, fornece "aos moços as necessarias e sufficientes luzes para o tirocínio da vida publica", e a mesma equiparação garante que os exames prestados no Lyceu sejam "validos para matriculas nos cursos superiores da Republica". (MORAES, 2011, p. 60).

Esta equiparação ao "Gymnasio Nacional”, hoje Colégio Pedro II, conferiu ao CEPC o status de "colégio padrão" no cenário paraense, sendo referência na qualidade de ensino e contribuiu para afirmação de sua tradição no contexto local e nacional.

Ao longo de sua história vem acumulando uma grande quantidade de fontes para que se possa compreender a educação no Pará, embora muitos documentos tenham se perdido com o descaso e/ou falta de ciência da importância deles e os que existem se encontrem em estado de grave deterioração, ainda é possível construir uma literatura nesse campo de estudo a partir do seu acervo. Nesse esforço, apresento a seguir dados sobre a presença negra na história da educação paraense, a partir desta instituição de ensino.

\section{A PRESENÇA NEGRA NO COLÉGIO ESTADUAL PAES DE CARVALHO}

A presença negra no Colégio Estadual Paes de Carvalho é trabalhada aqui a partir dos dados encontrados no Livro para registro de historico de funcionários $\left(\mathrm{n}^{\mathrm{o}} 1\right)$, presente no arquivo da escola. Este livro foi aberto de acordo com a portaria do Major Interventor, de 3 de março de 1933 e deveria conter o histórico dos funcionários do CEPC, à época, "Gymnasio Paraense". A seguir, a reprodução da página de abertura do livro, registrado no dia 8 de março de 1933, sob a direção do Prof. Honorato Filgueiras. 


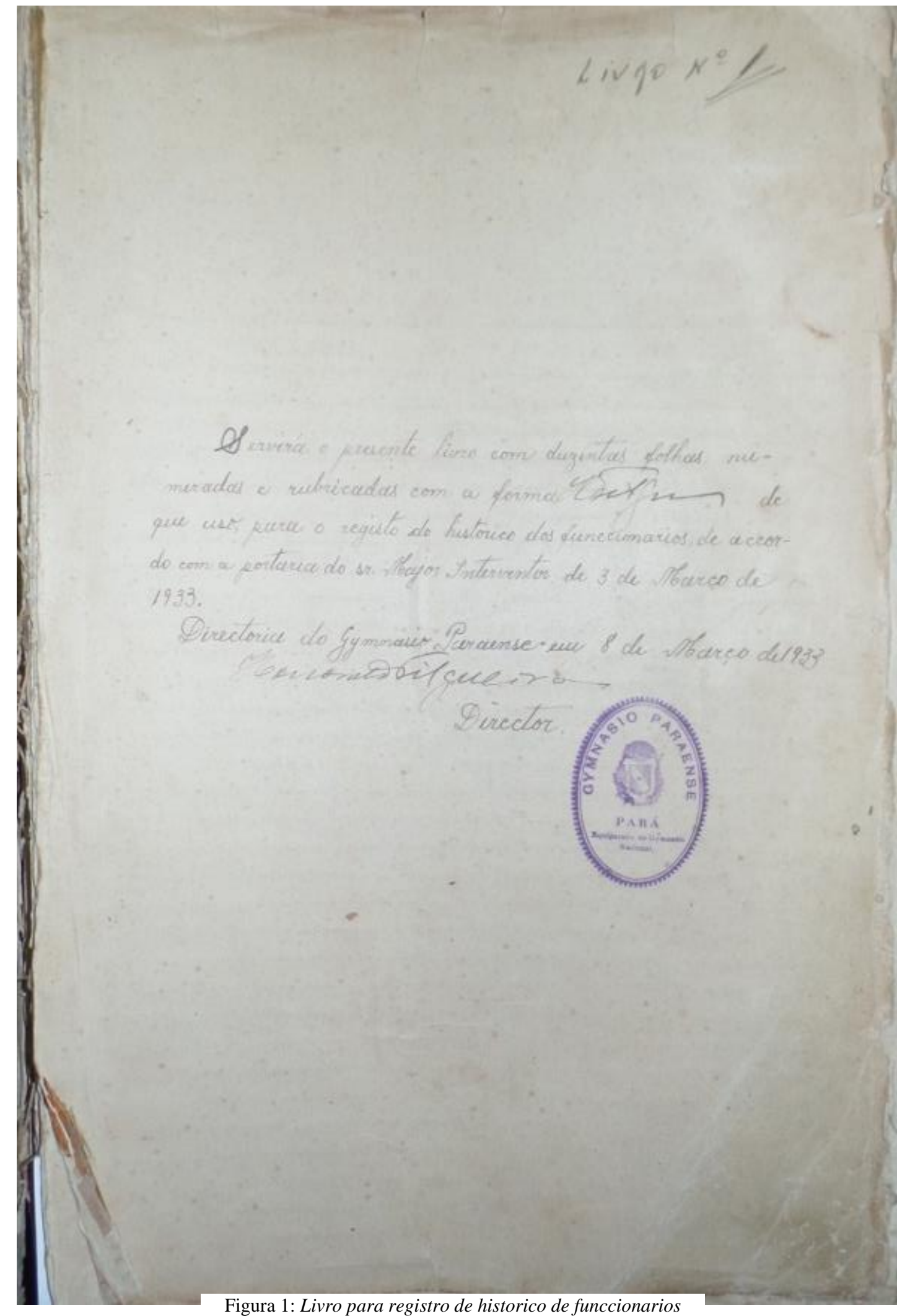
(OLIVEIRA, 2015)

As informações que deveriam constar no livro eram as seguintes: Geral: foto, nome e cargo; registro civil: filiação, naturalidade, nascimento e estado civil; "signaes": altura, 
cor, olhos, cabelos, barba, sinais particulares; registros sobre nomeação, promoção, transferência e exclusão; histórico. A seguir, o exemplo do preenchimento da ficha individual de um dos sujeitos da pesquisa:

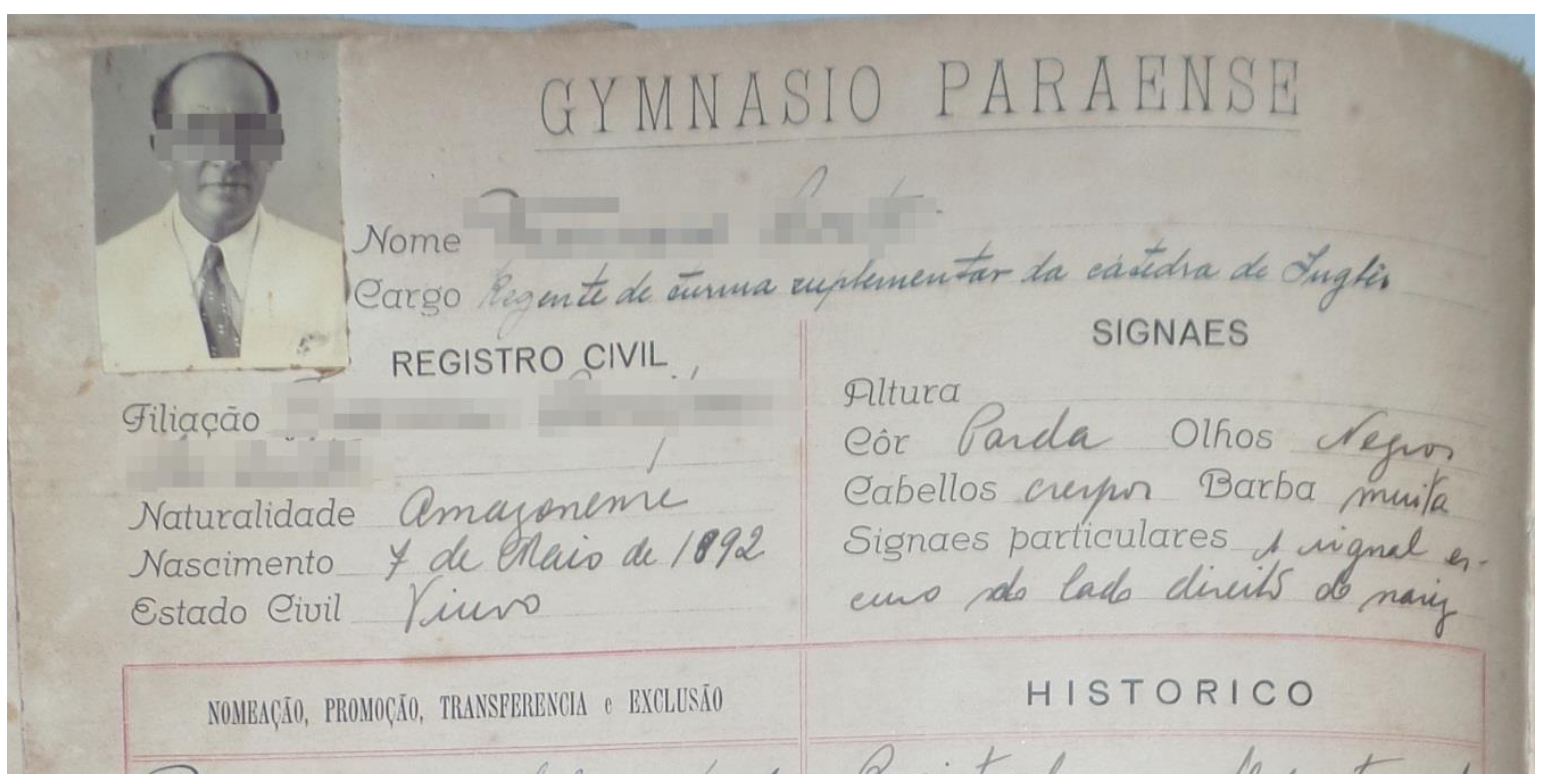

Figura 2: Registro de histórico de funcionário (OLIVEIRA, 2015)

Dentre os funcionários cujos registros estão presentes no livro, foram identificados 05 caracterizados como "pretos", "pardos" ou "morenos" e, por terem sido nomeados um ano após o fím do período da Primeira República, em 1931, momento em que o preconceito racial fora legitimado teoricamente pelas correntes ideológicas adotadas pelo movimento republicano, onde o negro e o mestiço eram "comprovadamente" inferiores e degenerados por razões genéticas. Com isso, a inquietação surgiu em torno do cargo que cada um, sendo negro, assumiria na instituição e quais as possibilidades de receberem promoção.

Os funcionários, suas respectivas características pessoais e histórico no "Gymnasio Paraense" estão apresentados a seguir, porém, sem que sejam revelados seus nomes e filiação com o intuito de resguardar sua identidade.

Funcionário A: Paraense, nascido em 11 de agosto de 1889. Moreno, cabelos e olhos pretos, barba raspada. Foi nomeado para reger interinamente a $2^{\mathrm{a}}$ cadeira de Matemática, em substituição ao catedrático Dr. João Dias da Silva, em 11 de setembro de 1931, entrando em exercício do seu cargo no mesmo dia. Não há registros do período em que ele permaneceu no cargo nem se foi efetivado.

Funcionário B: Pernambucano, nascido em 4 de setembro de 1886, casado. Moreno, $1,62 \mathrm{~m}$ de altura, cabelos pretos, olhos castanhos, barba raspada. Nomeado pelo Sr. Major Interventor J. Magalhães Barata, em 09 de janeiro de 1932, para reger interinamente a cadeira de História da Civilização. Em 02 de maio de 1936, foi nomeado para reger as turmas de Psicologia e Lógica do curso complementar da instituição, entrando em exercício de suas funções no mesmo dia. No dia 31 de julho de 1936, foi nomeado pelo Governador do Estado para exercer o cargo de professor de História da Civilização durante o período de licença do catedrático Dr. José Alves Maia, e entrou em exercício das funções deste cargo no dia 01 de agosto do mesmo ano. Ainda em 1936, em portaria ${ }^{\circ} 105$ de 24 de agosto, foi designado professor do Curso Complementar para lecionar interinamente a turma da classe didática de Direito, na cadeira de Noções de Economia Estatística, durante o impedimento do respectivo catedrático, Dr. Miguel José Pernambuco Filho. Permaneceu nesta função até o dia 30 de 
setembro de 1936, após o retorno do professor catedrático. Em 28 de dezembro de 1937, foi nomeado para exercer o cargo de Director efetivo. Foi requisitado para o Departamento Administrativo do Estado em 18 de julho de 1939.

Funcionário C: Acreano, nascido em 20 de fevereiro de 1909, casado. Moreno, cabelos castanhos, olhos pretos, barba raspada. Por portaria de 17 de agosto de 1932, foi transferido do Grupo Escolar Barão do Rio Branco do cargo de servente para assumir a mesma função no "Gymnasio Paraense", entrando em exercício no mesmo dia. Por decreto de 29 de maio de 1942, recebeu 45 dias licença, motivo não informado.

Funcionário D: Paraense, nascido em 12 de janeiro de 1905, solteiro. Preto. Nomeado em 09 de abril de 1935 para exercer o cargo de contínuo, entrando em exercício no dia 11 do mesmo mês e ano. Em virtude do ato do Governador do Estado, ficou exonerado em 29 de agosto de 1935, sendo substituído e havendo trabalhado até 31 do mesmo mês, dia em que se apresentou o novo nomeado.

Funcionário E: Amazonense, nascido em 7 de maio de 1892, viúvo. Pardo, cabelos crespos, olhos negros, muita barba, apresentava um sinal escuro do lado direito do nariz. Nomeado por decreto de 15 de abril 1942, atuou como regente da turma suplementar da cátedra de Inglês, assumindo o exercício no mesmo dia. Em 1943, por decreto do dia 30 de março, foi nomeado para a mesma função e entrou em exercício no dia 06 de abril. Possuía registro no departamento de Educação e Saúde, por portaria nº 169 de 29 de maio de 1939, no Ministro de Estado de Educação e Saúde.

O que pode ser percebido, a partir das informações obtidas nas fontes consultadas, é o fato da predominância de pessoas negras ocupando serviços com menor prestígio social, tais como servente ou contínuo, ou quando assumiam o cargo de professor, era na situação de interino/substituto, com chances quase nulas de receberem promoção e ocuparem cargos mais elevados.

Durante a coleta de dados, foram identificados, através das fotos da ficha individual, outros funcionários aparentemente negros, porém sem receberem essa classificação no campo "sinais", em sua maioria eram porteiros, serventes, inspetores de alunos e um único professor catedrático, aprovado em concurso, o Prof. Domingos Sylvio Nascimento, que ocupou a cadeira de História do Brasil no ano de 1922 e que se apresenta como objeto de estudo da dissertação de mestrado que estou construindo atualmente.

\section{CONSIDERAÇÕES FINAIS}

Este estudo, sem a pretensão de realizar uma análise aprofundada acerca do papel da pessoa negra na educação escolar paraense até a primeira metade do século XX, apresenta dados reais a respeito da posição do negro neste contexto, indicando quais lugares ele ocupou na hierarquia da escola naquele período histórico.

Não sendo possível concluir este trabalho com respostas fechadas, faço, aqui, o que propus neste estudo, lanço questões para instigar discussões futuras e provocar novas reflexões sobre este objeto.

Ainda que possa parecer óbvio, o que, realmente, pode representar o fato de que, apenas após o ano de 1931 - considerando que anteriormente era fortemente defendida e teoricamente sustentada a suposta inferioridade da pessoa negra - o CEPC passou a contratar funcionários morenos, pardos e pretos, tendo, antes disso, um único professor negro?

O que explica a inclusão dos termos "moreno", "pardo" e "preto" nas fichas individuais daqueles que ocupavam os cargos de contínuo, servente ou professores 
interinos/substitutos? Por que as fichas de inspetores de alunos e porteiros não apresentavam resposta no item "cor", mesmo que suas fotos mostrassem seus traços e pele negra?

Por que o primeiro professor catedrático negro registrado no livro de histórico de funcionários da instituição, embora tivesse ocupado várias páginas com sua "louvável" trajetória, não teve, em nenhuma delas, o item "cor" preenchido?

Por que o único, dentre os sujeitos deste estudo, a ter em seu histórico a situação "exonerado" foi, também, o único a ser classificado como "preto"?

Penso que são questões que devam receber atenção de pesquisadores não só em História da Educação, mas também de outras áreas. São reflexões que não podem permanecer apenas no senso comum, mas que precisam ser amplamente discutidas a partir de um aparato teórico-metodológico consolidado.

\section{REFERÊNCIAS}

- Fontes documentais

"Livro para registro de historico de funcionários (n $\left.{ }^{\circ} 1\right)$ ". Aberto sob a direção do Professor Honorato Filgueiras. Belém: Gymnasio Paraense, 1933.

- Bibliografia

CHAQUIAM, Miguel; GASPAR, Elaine da S.; BORGES, Gleeydson F. L. Recortes Históricos do Liceu Paraense ao Colégio Estadual Paes De Carvalho. Anais do X Encontro Nacional de Educação Matemática (Pôster). Salvador: Sociedade Brasileira de Educação Matemática, 2010.

CURY, Carlos R. Jamil. Ideologia e Educação Brasileira: Católicos e liberais. 4. ed. São Paulo: Cortez - Autores Associados, 1988.

FRANÇA, Maria do Perpétuo Socorro G. de S. A. de. Raízes históricas do ensino secundário público na Província do Grão-Pará: O Liceu Paraense (1840-1889). Dissertação (mestrado). Orientadora: Maria Elizabete Sampaio Prado Xavier. Universidade Estadual de Campinas, Faculdade de Educação. Campinas, 1997.

LE GOFF, Jacques. Documento/Monumento. In.: História e Memória. 4. ed. Campinas: Unicamp, 1996.

MORAES, Felipe Tavares de. A educação no Primeiro Governo de Lauro Sodré (18861897): os sentidos de uma concepção político-educacional republicana. Dissertação de Mestrado. Programa de Pós-Graduação em Educação - UFPA. Belém, 2011.

REGO, Clóvis Moraes. Subsídios para a história do colégio estadual 'Paes de Carvalho'. Belém: Ed. da UFPA, 2002.

RIBEIRO, Joyce Otânia Seixas. A tradução da tradição em práticas curriculares no Colégio Estadual Paes de Carvalho. Orientadora: Josenilda Maria Maués da Silva. Tese (Doutorado) - Universidade Federal do Pará, Instituto de Ciências da Educação, Programa de Pós-Graduação em Educação, Belém, 2013. 
RODRÍGUEZ, Margarita Victoria. Pesquisa Histórica: o trabalho com fontes documentais. In.: COSTA, Célio Juvenal; MELO, Joaquim José Pereira e FABIANO, Luiz Hermenegildo. Fontes e métodos em história da educação. Dourados: Ed. UFGD, 2010.

SALLES, Vicente. O negro no Pará, sob o regime da escravidão. Rio de Janeiro: Fundação Getúlio Vargas; Universidade Federal do Pará, 1971.

VERÍSSIMO, José. A Educação Nacional. 3. ed. Porto Alegre: Mercado Aberto, 1985.

\footnotetext{
${ }^{2}$ Licenciada Plena em Pedagogia pela Universidade do Estado do Pará - UEPA. Mestranda em Educação, na linha de Educação: currículo, epistemologia e história, do Programa de Pós-Graduação em Educação do Instituto de Ciências da Educação da Universidade Federal do Pará, sob a orientação da Profa. Dra. Maria José Aviz do Rosário. Integrante do Grupo de Estudos e Pesquisas "História, Sociedade e Educação" - HISTEDBRSecção Pará.

${ }^{2}$ Optou-se por utilizar a nomeação atual da escola "Colégio Estadual Paes de Carvalho" para evitar possíveis dúvidas, pois, no recorte cronológico do estudo, a instituição sofreu duas alterações de denominação. No ano de 1922, a escola se chamava "Ginásio Paes de Carvalho"; em 1930 recebeu o nome "Ginásio Paraense"; por fim, no ano de 1942, passou a ser chamada de "Colégio Estadual Paes de Carvalho" (CHAQUIAM, GASPAR e BORGES, 2010).

${ }^{3}$ Ribero (2013), em sua tese de doutorado intitulada "A tradução da tradição em práticas curriculares no Colégio Estadual Paes de Carvalho", aborda essa reinvenção do uniforme escolar do CEPC, sobretudo pelas alunas, as chamadas Belíssimas, e pelos alunos gays, as Lorranys.
}

Recebido: mai/15 Aprovado: jun/15 